Article

\title{
Sustainable Technologies and Social Costs for Eliminating Contamination of an Aquifer
}

\section{Mario Schirmer ${ }^{1}$ and Horst Niemes ${ }^{2, *}$}

1 Eawag, Swiss Federal Institute of Aquatic Science and Technology, Überlandstraße 133, P.O. Box 611, CH-8600 Dübendorf, Switzerland; E-Mail: mario.schirmer@eawag.ch

2 Helmholtz Centre for Environmental Research-UFZ, Permoserstraße 15, D-04318 Leipzig, Germany

* Author to whom correspondence should be addressed: E-Mail: email@ horst-niemes.de; Tel.: +41-44-823-5382; Fax: +41-44-823-5210.

Received: 30 May 2010; in revised form: 25 June 2010 / Accepted: 9 July 2010 /

Published: 16 July 2010

\begin{abstract}
This case study deals with long-term contamination of the Leuna aquifer, which is intended to be restored using sustainable technologies financed by the state. The contamination can only be solved using active rather than passive intervention, because the aquifer has an extraordinarily low natural attenuation capacity for the specific pollutants. Due to the longevity of the contamination source, the groundwater treatment technology that was chosen for the site must operate for a minimum of 20 years but probably much longer. Since the polluter-pay principle cannot be applied, the estimated dynamic primary remediation costs must be accepted as a political or social cost, which must be paid by current and future generations.
\end{abstract}

Keywords: groundwater contamination; MTBE-remediation technologies; social costs for groundwater rehabilitation measures

\section{Introduction}

Large-scale groundwater contamination is a wide-spread problem at industrial sites throughout the developed world. Leuna is one example in Eastern Germany, which was a center of chemical production for about 100 years (Figure 1). MTBE (Methyl tertiary-butyl ether) is the compound which 
replaced tetra-ethyl lead to increase the octane rating of gasoline and helps to prevent engine knocking. MTBE has been used at the Leuna site since 1981 and was produced on a large scale in the former refinery starting in 1984. The refinery was closed in 1996. During the production period, large quantities of gasoline containing MTBE were introduced into the subsurface by spills during the handling processes or from leaking underground storage tanks. As a result, the subsurface at the former refinery is contaminated with different gasoline components, particularly BTEX (benzene, toluene, methylbenzene and xylenes) aromatics and MTBE are released into the groundwater.

Figure 1. A schematic view of the Leuna site plan.

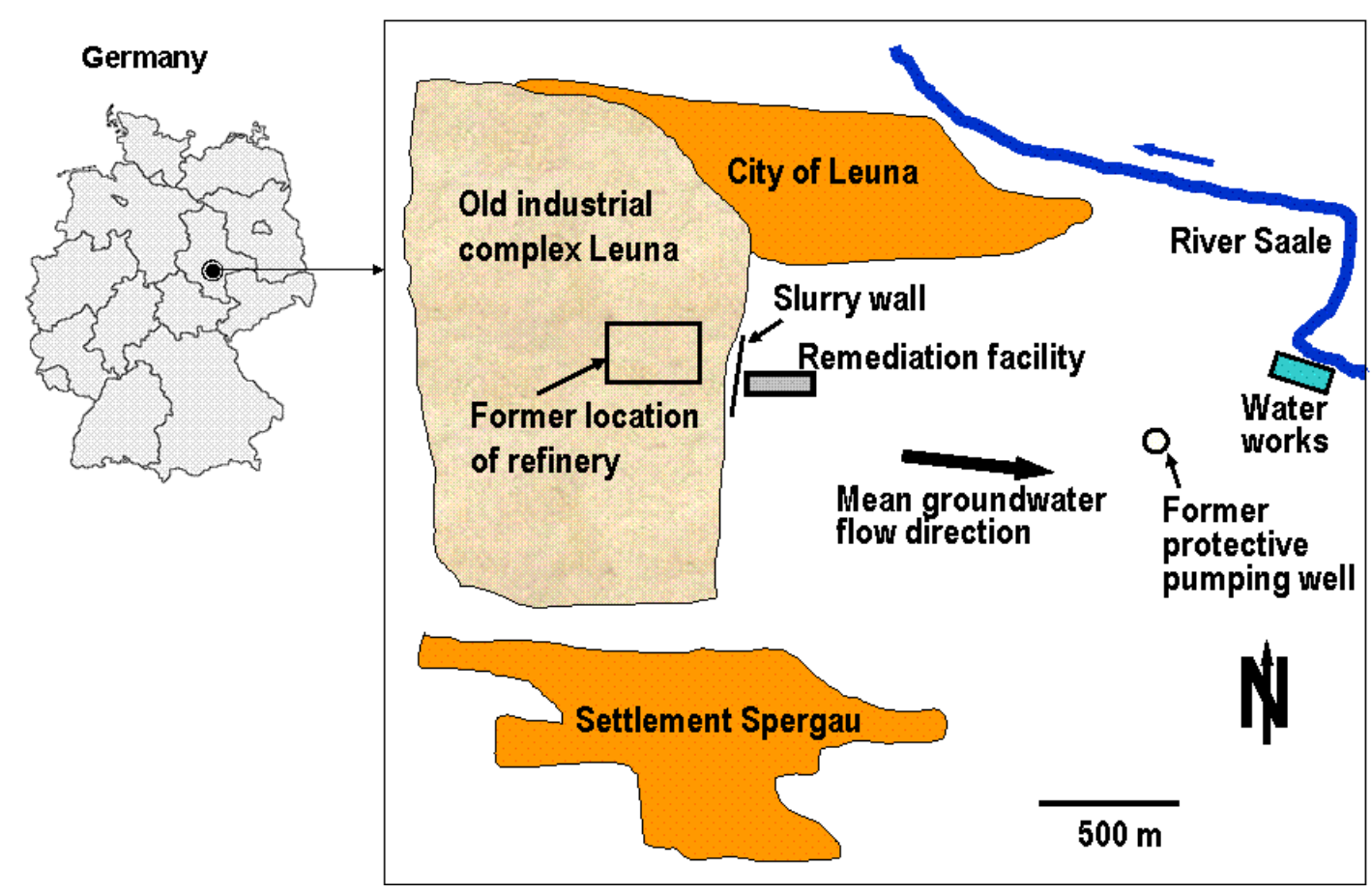

The aim of this paper is to estimate the social costs (or benefits) for a sustainable technological solution realized for the Leuna aquifer, which balances the failure of past activities with the interests of future generations. A huge number of natural science and engineering publications about this serious pollution problem, exist but there is a lack to estimate the social benefits gained by the solutions implemented and in operation at least for the next 20 years.

The dissolved pollutants are transported by groundwater flow. Downstream of the contaminant source are different objects that could potentially be impacted by the groundwater pollutants. The groundwater is flowing towards the Saale River, which is located approximately 2,000 m downstream of the spill sites.

The city of Leuna is located to the northeast of the industrial site. MTBE has already been detected in low concentrations in the drinking water wells being right adjacent to the river Saale. To prevent MTBE contamination in the drinking water wells of the Daspig water works, a protective pumping well $1,500 \mathrm{~m}$ downstream of the source zone and $500 \mathrm{~m}$ upstream of the drinking water wells was installed.

The hydrogeological and geochemical structure of this site has been investigated in great detail [1]. The main aquifer thickness is $2-4 \mathrm{~m}$ and the groundwater table is located approximately 3-4 m below 
the ground surface. The aquifer is relatively heterogeneous and is composed of fine to coarse sand and gravel. The hydraulic conductivity $(\mathrm{K})$ was calculated from hydraulic tests, grain size analyses, column experiments, and in situ tracer experiments. The mean $\mathrm{K}$ value is $4 \times 10^{-4} \mathrm{~m} / \mathrm{s}$ (medium to coarse sand and gravel), but it varies between different aquifers and ranges between $6 \times 10^{-2} \mathrm{~m} / \mathrm{s}$ in coarse gravel and $9 \times 10^{-5} \mathrm{~m} / \mathrm{s}$ in the medium to fine sand areas. The groundwater flow velocity was estimated using water level data, pumping, and tracer tests and it varies between $0.3 \mathrm{~m} /$ day and $1.0 \mathrm{~m} /$ day. The main flow direction is southwest to northeast. Due to the presence of hydraulic barriers, the flow direction changes within the investigation site to a west-east direction. The groundwater temperature varies between $7{ }^{\circ} \mathrm{C}$ and $14{ }^{\circ} \mathrm{C}$ (mean $11{ }^{\circ} \mathrm{C}$ ) depending on the location of the sampling wells and the season.

The economic rationale behind the joint use of the aquifer is based on economies of scale for essential components, which have the characteristics of local public goods because no competition or exclusion exists between users. In reality, however, a limited number of beneficiaries have access to a public good because of natural, technical, economical, administrative, or other constraints. Under these circumstances, a groundwater aquifer has local public or local club good if jointly used for the water supply services of a community and other ecosystem services such as the natural attenuation potential.

The hydrogeological characters of an aquifer are considered as local public good. This local public good has also the characteristics of a natural capital stock variable which should be maintained and protected. The recharged and extracted water of the aquifer, however, is a flow variable which has private good characteristics but also belonging to the basic right, which is not a commodity in economic terms that can be bought and sold.

In economic theory, the handling of public goods is independent of its specific type. Samuelson [2] and Musgrave [3] derived optimal conditions for public goods and expenditures on a governmental level. The sum of marginal benefits for each of the consumers must be equal to the total marginal benefit of the offered public good. Tiebout ([4], p. 419), however, showed that the optimal amounts of local public goods in different locations, which are in competition to attract people to one location, can only be achieved under less realistic and more extreme assumptions.

In this context, some specific patterns of the MTBE-contaminated aquifer at Leuna must be discussed. The decisions made after the unification of West and East Germany clarified the responsibility for the rehabilitation measures. It was decided that the economy of East Germany had to be reactivated. This site in particular, which was and is now again one of the main chemical industry centers, should not be hindered by social costs normally paid in accordance with the polluter-pay-principle. The publicly owned agency "Landesanstalt für Altlastenfreistellung des Landes Sachsen-Anhalt" (LAF) (State Agency for Redemption of Liability Saxony-Anhalt) was established by law on 25.10.1999. It was declared responsible for solving these contamination problems over the coming decades with the financial resources of the public community, but almost free of charge for the private companies settling at this site and at other sites within Saxony-Anhalt. 


\section{Results and Discussion}

\subsection{Technical Solutions for Reducing MTBE Contamination}

The remediation measures already implemented and financed by the LAF divide the aquifer into different sub-systems (Figure 2). The $400 \mathrm{~m}$ long and $15 \mathrm{~m}$ deep slurry wall separates the aquifer into local "bad" and "good" sections. The severely contaminated (contaminant source) "bad" section is upstream of the wall and the contamination-free "good" section is downstream of the wall. The pollution source (economic: stock) (I) in Figure 2 is the highly MTBE-contaminated subsurface sediment of the upstream aquifer, which is permanently polluting the aquifer (II). The MTBE peak concentrations in the groundwater are up to $125 \mathrm{mg} / \mathrm{L}$ and on average about $20 \mathrm{mg} / \mathrm{L}$. These levels are significantly above acceptable environmental standards for this and other pollution parameters. The combination of the large amount of MTBE stored in the surface soil along with the limited dilution and degradation capacity as well as the slow groundwater velocity means that the natural attenuation on the flow path will not be high enough to reach drinking water standards before the groundwater will reach the river or water works. Therefore, there is a need to remediate the contaminated groundwater that is extracted upstream of the wall (III) in a treatment plant (IV) and to infiltrate the treated groundwater (V) into the downstream section of the aquifer (VI).

Figure 2. Water infrastructure implemented to solve the contamination problem of the Leuna aquifer.

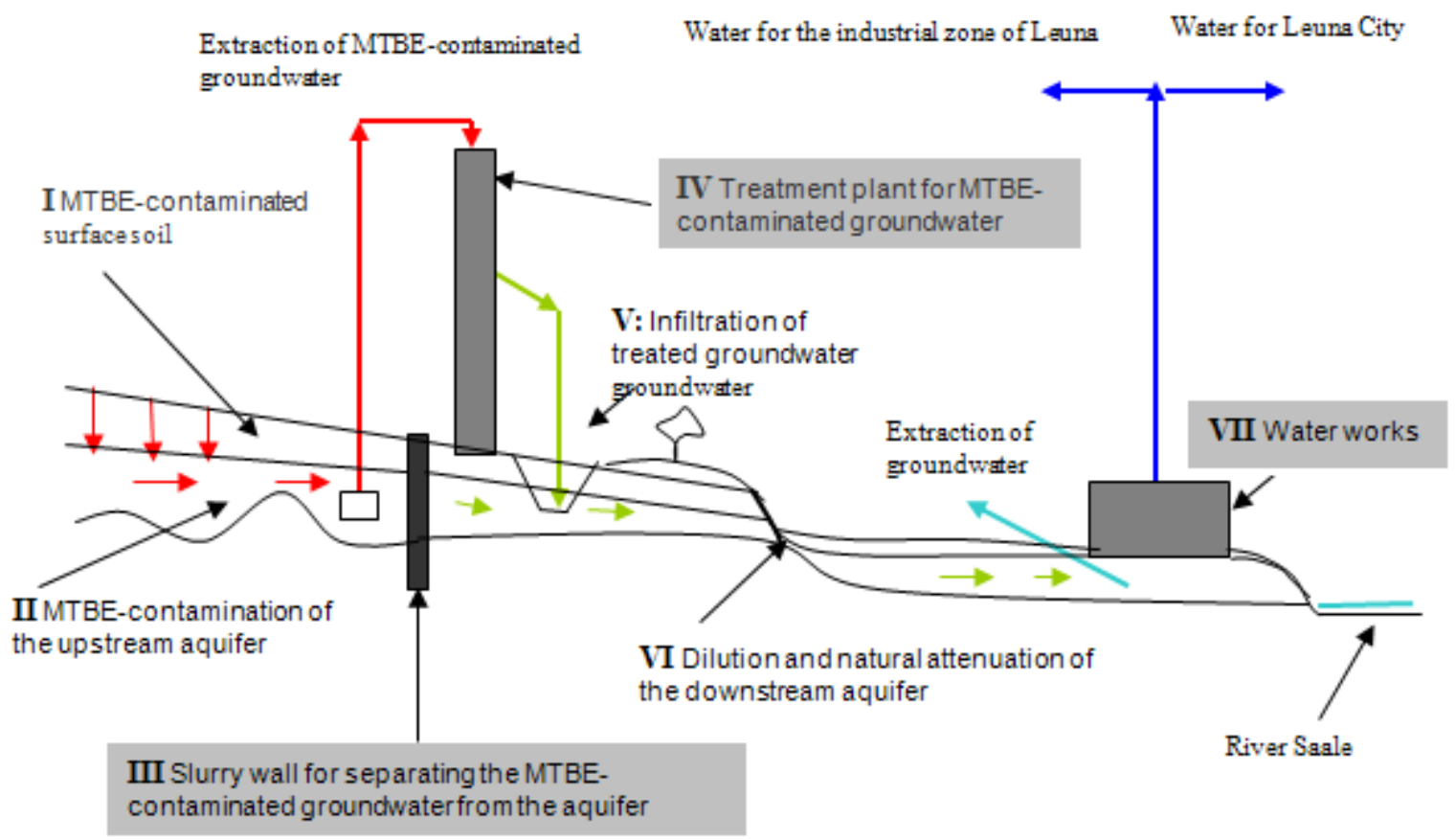

As requested by the authorities, the treatment technologies should reduce the MTBE concentration in water to a level of $200 \mu \mathrm{g} / \mathrm{L}$. The drinking water standard is $5 \mu \mathrm{g} / \mathrm{L}$ and this is the concentration that must be achieved at the drinking water wells of the water production plant (VII) located $1.5 \mathrm{~km}$ downstream. Reduction of the concentration from 200 to $5 \mu \mathrm{g} / \mathrm{L}$ will be achieved through dilution and the natural attenuation capability of the downstream aquifer (for more details see [1] and [5]). The 
remaining risks can be reduced by additional measures. These additional measures include eliminating localized pollution sources in the downstream aquifer and removing the MTBE-contaminated soil.

There are no known MTBE problems in the new drinking water works, which have a capacity of $220 \mathrm{~m}^{3} / \mathrm{h}$ or $5,280 \mathrm{~m}^{3} /$ day and serves 7,500 inhabitants in the city of Leuna as well as the industrial complex of Leuna. The chosen raw water quality standard and remediation strategy therefore seems to be acceptable.

After a long period of investigation, the different MTBE treatment options were narrowed down to two. The two chosen concepts were an external treatment that uses so-called stripping technologies, and an internal biological treatment, where microbiological processes are accelerated by oxygen addition. The second technology required further investigation because it is not state-of-the-art. The so-called OXYWALL application had thus far only been performed within the pollution source zones. As a result, effective downstream results could not be demonstrated. If plume remediation were done, this technology might be much more successful and cost-effective, but it would still require a long reaction space.

Air stripping was chosen as the most common on-site groundwater treatment technology. With air stripping, volatile organic contaminants in the dissolved phase are transferred into the vapour phase, by blowing air through the contaminated water. Contaminated water is trickled from the top of a large tower while air is introduced from the bottom. Air stripping is effective for petroleum hydrocarbons but will be less efficient for MTBE because of its moderate volatility in the aqueous phase. The Henry's Law constant, $\mathrm{H}$, of about 0.04 for MTBE is much lower, for example, than the 0.222 for benzene [6]. MTBE's lower volatility requires either a higher air-to-water ratio or heated air for accelerating the air stripping removal efficiency. The air is later cleaned by passing it through an activated carbon filter. This technique can meet the regulatory limits for water that is to be re-injected into the aquifer, commonly at concentrations less than $100 \mu \mathrm{g} / \mathrm{L}$. However, if MTBE must be completely eliminated, then air stripping becomes highly expensive.

A feasible alternative to on-site treatment technologies is the enhanced natural attenuation (ENA) approach. ENA through direct gas injection or conditioning treatment facilities can be highly effective. It can be adapted to either low or high contaminant concentrations. However, in many cases, using ENA as a remediation technology requires large reaction zones in the aquifer.

One of the simplest ENA methods for MTBE remediation is adding oxygen to the groundwater by air sparging. The main advantages of sparging technologies are the simple technical equipment and low costs. Air sparging can be used for the elimination of MTBE concentrations up to $40 \mathrm{mg} / \mathrm{L}$ (for more details see e.g., [7,8]). One disadvantage of air sparging is a gas clogging effect. Nitrogen bubbles that remain after the oxygen is consumed reduce the water-filled porosity and the permeability of the aquifer in the treatment zone. This reduced permeability may result in a partial bypass of contaminated groundwater around the treatment zone. Therefore, recent treatment technologies inject pure oxygen instead of air. Oxygen sparging has been successfully applied by different investigators and at a number of sites [9-12].

Oxygen injection systems can operate continuously or intermittently. Continuous oxygen injection commonly provides higher dissolved oxygen concentrations than intermittent injection. On the other hand, increased gas saturation in the aquifer can significantly reduce the hydraulic conductivity. This gas clogging is not only the result of excess oxygen supply, but also results from increased 
accumulation of dissolved nitrogen and other permanent gases in the air bubbles [13]. Therefore, periodic oxygen gas injection has been preferred in most applications. Trapped gas bubbles remaining in the aquifer provide the groundwater with oxygen for extended periods between the gas injection cycles. Optimized intervals between subsequent gas injections allow the remaining nitrogen and other permanent gases to re-dissolve and prevent significant gas clogging.

Optimal conditions depend on the concentrations of pollutants, oxygen demand of the different site reactions, and on the geological and hydrogeological setting. For oxygen sparging, injection wells are installed in the aquifer at different locations and depths depending on the geological structure of the aquifer and the measured MTBE concentration.

\subsection{Estimation of the Extent of MTBE Contamination}

The MTBE contamination is extensive and must be considered a serious source of pollution because the natural attenuation capacity of the aquifer is limited. The actual amount of MTBE that has discharged to the Leuna aquifer is unknown. Therefore, we can only estimate the amounts indirectly. A wall that is $400 \mathrm{~m}$ long and $15 \mathrm{~m}$ deep divides the aquifer. If we assume a $200 \mathrm{~m}$ length of wall with an aquifer thickness of $2 \mathrm{~m}$ to $4 \mathrm{~m}$ and a groundwater velocity between 0.3 and $1.0 \mathrm{~m} /$ day, we can estimate groundwater flow volumes in the range of $120 \mathrm{~m}^{3} /$ day to $800 \mathrm{~m}^{3} /$ day.

The wells constructed for collecting the polluted groundwater were constructed to have a capacity of about $12 \mathrm{~m}^{3} / \mathrm{h}$ to $15 \mathrm{~m}^{3} / \mathrm{h}$ or $288 \mathrm{~m}^{3} /$ day to $360 \mathrm{~m}^{3} /$ day. This range, being relevant for further calculations, lies at least within the range for the groundwater flow volumes estimations. Due to the lack of precise groundwater flow volumes, a pilot remediation plant has been in operation for 15 months to collect data for optimizing the final groundwater treatment plant (for more details see [14]).

If we use the estimated average MTBE concentration of $20 \mathrm{mg} / \mathrm{L}\left(20 \mathrm{~g} / \mathrm{m}^{3}\right)$ then the daily MTBE mass flux transported by the aquifer and extracted by groundwater treatment would be in the range of $5.76 \mathrm{~kg} /$ day to $7.3 \mathrm{~kg}$ /day $(2.1 \mathrm{t} / \mathrm{y}$ to $2.6 \mathrm{t} / \mathrm{y})$. The treatment facility reduces the average MTBE concentration from $20 \mathrm{mg} / \mathrm{L}$ to $200 \mu \mathrm{g} / \mathrm{L}$. The self-purification and dilution capability then further reduces the concentration to $5 \mu \mathrm{g} / \mathrm{L}$. It is estimated that the treatment facility will operate for 20 to 30 years. Using these data, the total MTBE amounts are estimated to be between 42 and 78 tonnes. MTBE production took place over a period of 10 years before environmental protection measures were put in place. Therefore, it is estimated that $4.2 \mathrm{t} / \mathrm{y}$ to $7.8 \mathrm{t} / \mathrm{y}$ were discharged into the Leuna aquifer. Although this is a rough estimate, it is a realistic value when considering past production practises.

Even though only a rough estimate of MTBE pollution is possible, the change in concentration from $20 \mathrm{mg} / \mathrm{L}$ to $200 \mu \mathrm{g} / \mathrm{L}$ after groundwater treatment and to $5 \mu \mathrm{g} / \mathrm{L}$ for the drinking water standard are very ambitious targets from a thermodynamic point of view. Reducing the MTBE concentration from $c_{M}^{0}=20 \mathrm{mg} / L$ to the emission standard of $c_{M}^{T}=200 \mu \mathrm{g} / L$ requires large free energies for returning this irreversible process (for more details see [15], Chapter 2).

\subsection{The Target Group of the Rehabilitation Measures}

The new Daspig drinking water works is the main water supplier for the town of Leuna. It extracts raw water from the Saale River bed infiltration and groundwater from the Leuna aquifer, but also by drinking water wells adjacent at the other river side. Consequently, the new water work could have 
also been constructed at the other river side with minor influence on the investment costs roughly estimated to be less than 20 million $€$.

Although there are no known, direct, negative influences from the MTBE pollution stock on the raw water quality, the town of Leuna and the industrial site can be considered as target groups for rehabilitating this local public good, for which a potential risk still remains. As a result, the rehabilitation of the Leuna aquifer is not a question of economic optimization, but a political decision to reduce future risks caused by economic activities in the past. This means that the emission standard price approach can be applied instead of optimizing a welfare function under given constraints for the target group. It is sufficient to estimate the dynamic prime costs of the rehabilitation measures, which reflects the social costs caused by polluting the Leuna aquifer. The time it takes to rehabilitate the aquifer is determined by the natural aquifer conditions, the technology chosen to eliminate MTBE pollution, and also political decisions. The dynamic prime costs can also be interpreted as a shadow price of the willingness to return the aquifer over time to its original natural state.

The polluter-pay principle cannot be applied in this special case, because the polluter and owner of the former chemical plants, the East German state, the German Democratic Republic does not exist anymore. Therefore, it is a matter of justice that these social costs should be paid by the government from the tax income. This means that the social costs are not directly paid by individuals, but indirectly paid as part of the taxes transferred to the government, which subsidizes these rehabilitation measures.

\subsection{Estimation of the Social Costs for Solving the MTBE-Contamination Problem}

The authorities' clear intention is to find a sustainable and cost-effective solution for the remediation process. However, the social costs of the groundwater contamination are influenced by political decisions. In the case of the Leuna aquifer, there were many of these decisions. One example was the choice of the 20 to 30 year time horizon of the cleanup. Another decision was to use the natural attenuation capacity of the aquifer. This could be a cost-effective solution because any contaminant plume will finally come to a quasi-steady-state extent. If it can be accepted that the encountered aquifer volume is contaminated for a long period of time, only monitoring is required. After a certain period, which can take decades or even centuries, the contamination will disappear. This is due to dissolution, dilution as well as biotic and abiotic degradation processes in the contaminant source and the plume. The serious drawback of this solution is the excessive length of the plume which would be required, estimated for MTBE at this site to be several $\mathrm{km}$. This solution, however, would be sustainable only if the aquifer as a local public good is not needed for other purposes.

Finally, the technological and financial opportunities of reducing the MTBE pollution were also factors in the decision-making process. When calculating the so-called dynamic prime costs (DPC), which reflect the shadow prices of the social costs caused in the past and the future prices of the groundwater rehabilitation measures, we should keep in mind that the costs for treating the groundwater and infiltrating it back into the downstream aquifer are political prices.

The dynamic prime costs are defined as follows: 


$$
\mathrm{DPC}=\frac{\mathrm{NPVC}}{\mathrm{NPVW}}=\frac{\left\{\sum_{\tau=1}^{\mathrm{T}} \frac{\{\mathrm{I}(\tau)+\mathrm{O}(\tau)\}}{(1+\delta)^{\tau-1}}\right\}-\frac{\mathrm{RVI}(\mathrm{T})}{(1+\delta)^{\mathrm{T}}}}{\sum_{\tau=1}^{\mathrm{T}} \frac{\mathrm{W}(\tau)}{(1+\delta)^{\tau-1}}}
$$

where, $\mathrm{W}(\tau)$, is the amount of groundwater to be treated, T the time horizon, $\mathrm{I}(\tau)$ the investment cost, $\operatorname{RVI}(\mathrm{T})$ the residual value of the investment costs at the end of the planning horizon, $\mathrm{O}(\tau)$ the operation costs, and $\delta \geq 0$ the exogenously given discount rate.

The sum of the discounted investment and the operation costs minus the discounted residual value of the investment costs are called the net present values of the costs. The sum of the discounted groundwater amounts is called the net present value of the groundwater amounts.

\subsubsection{Amount of Groundwater and Time Scale}

Based on the experience with the pilot remediation plant that was constructed to optimize the groundwater treatment technology, the groundwater amounts to be treated by the stripping plant range from $12 \mathrm{~m}^{3} / \mathrm{h}$ to $15 \mathrm{~m}^{3} / \mathrm{h}$. The variation in the amount of extracted groundwater is caused by meteorological conditions. The average groundwater flow rate of $14 \mathrm{~m}^{3} / \mathrm{h}\left(336 \mathrm{~m}^{3} /\right.$ day or $\left.122.640 \mathrm{~m}^{3} / \mathrm{a}\right)$ fits within the range of $160 \mathrm{~m}^{3} /$ day to $640 \mathrm{~m}^{3} /$ day as estimated above. This average rate will be assumed to remain constant during the time period of groundwater treatment.

It is estimated that the groundwater treatment plant will operate over a time horizon of at least 20 , and up to 30 years. When calculating net present values or dynamic prime costs, the values of the costs and groundwater amounts must be discounted, which means that the values at later time intervals are less relevant. In order to be conservative, a time horizon of 30 years will be assumed.

\subsubsection{Investment Costs}

The main financial investment for the groundwater treatment measures was done in 2004 and included the following items:

1. The $400 \mathrm{~m}$ slurry separation wall $980,000 €$

2. The water storage during construction $60,000 €$

3. The system for draining groundwater to the treatment plant $490,000 €$

4. The groundwater treatment plant $195,000 €$

5. The pilot plant for optimizing the treatment process

6. Supplementary measures

7. Total

$2,039,000 €$

These investment measures were based on hydrogeological investigations, which cost approximately 400,000 € from 2001 to 2004 . These preparatory investment costs can be aggregated and added to the first three items of the investment costs, to obtain a total investment cost up until 2004 of 1,530,000 €. For the other three investment costs, which total 509,000 $€$ (the water treatment plant and its pilot phase, and the supplementary measures), we assume that they went into operation in 2005. The investment costs for 2004 and 2005 are 2,439,000 €. 
For the elimination of the remaining contaminant, additional investment costs of 4-5 million $€$ are expected. We will assume that these additional costs are equally distributed over six years, which means that approximately $643,000 €$ will be invested over the time interval from 2009 to 2015 .

Complementary measures such as the excavation, treatment, and disposal of the contaminated soils have been conducted since 1991 and will continue into the future. These complementary measures are estimated to cost 40 million $€$, but are not considered as part of the aquifer restoration. Therefore, these costs are not included in the calculation of the dynamic prime costs. In this context, it should be mentioned that the companies that move onto the industrial site at Leuna must pay for a portion of these complementary measures, usually $10 \%$.

\subsubsection{Residual Values of the Investment Costs at the End of the Planning Horizon}

The additional investment costs of 4.5 million $€$ between 2009 and 2015 are assumed as costs at 2009 prices and then discounted when calculating the dynamic prime costs. The $250,000 €$ for supplementary measures and the future investment costs are mainly for eliminating pollution sources. These investments can be considered as modifying the natural conditions, which will remain forever. As a result, the residual values of these investments at the end of the planning horizon are equal to the investment costs. The separation wall and the drainage system are typical civic works and can be expected to last at least 60 years. Therefore, their residual value will be assumed to have half of the value of the previous investment costs at the end of the planning horizon, 735,000 €. The residual value of the groundwater treatment plant, however, will be set to zero. With these assumptions, the total residual value of all investment costs sum to a value of 5,485,000 €, which will be considered has negative output value at the end of the planning horizon because the investment and operation costs are positive inputs when calculating the dynamic prime costs. Thus the input and output values are discounted in accordance to its time structure, the influence of later investments and especially of the residual value is comparable low.

\subsubsection{Fixed and Variable Operation Costs}

The fixed operation costs for the maintenance and operation of the groundwater treatment facilities are approximately 120,000 €/a. Estimates of the variable operation costs for energy, chemicals, etc. range from 0.6 to $1.2 € / \mathrm{m}^{3}$ of treated groundwater. Based on an average of $0.9 € / \mathrm{m}^{3}$, the annual variable operations costs amount to $110,376 € / \mathrm{a}\left(0.9 € / \mathrm{m}^{3} \times 122,640 \mathrm{~m}^{3} / \mathrm{a}\right)$. For the year 2004, however, only half the operations costs will be assumed because the facilities were in full operation at the beginning of 2005 .

\subsubsection{Net Present Value and Dynamic Prime Costs}

Figure 3 outlines the calculation of the dynamic prime costs for the treatment of the Leuna aquifer. Based on a discount rate of $5 \%$ (equal to a discount factor of 1.05), Figure 3 shows the net present value of all investment and operation costs results in a value of 7,809,963 € for the entire planning period. When dividing this net present value by the net present value of the groundwater volume $\left(1,979,541 \mathrm{~m}^{3}\right)$, we obtain a dynamic prime cost (DPC) of $3.95 € / \mathrm{m}^{3}$. This value is relatively 
high and it is also very sensitive to the additional investment over the next seven years. If these additional investment costs cannot be related directly to the aquifer under consideration, the dynamic prime costs are much lower. They cannot be lower than $2.93 € / \mathrm{m}^{3}$ because this would create the situation where no additional investment costs would be required. If the total investment costs are not included in the calculation, the dynamic prime costs for only the operation costs would be $1.82 € / \mathrm{m}^{3}$.

Figure 3. Calculation of the dynamic prime costs for water treatment of the Leuna aquifer.

\begin{tabular}{|c|c|c|c|c|c|c|c|c|c|}
\hline \multirow[b]{2}{*}{ Year } & \multicolumn{2}{|c|}{ Investment Costs } & \multicolumn{2}{|c|}{ Operation Costs } & \multirow[t]{2}{*}{ Total Costs } & \multirow{2}{*}{$\begin{array}{l}\text { Groundwater } \\
\text { Amount }\end{array}$} & \multirow{2}{*}{$\begin{array}{l}\text { Discount } \\
\text { Factor } \\
\qquad 1,05\end{array}$} & \multirow{2}{*}{$\begin{array}{l}\text { Discounted } \\
\text { Costs }\end{array}$} & \multirow{2}{*}{$\begin{array}{l}\text { Discounted } \\
\text { Groundwater } \\
\text { Amounts }\end{array}$} \\
\hline & Original & Additional & Fixed & Variable & & & & & \\
\hline & $€ / a$ & $€ / a$ & $€ / a$ & $€ / a$ & $€ / a$ & $\mathrm{~m}^{3} / \mathrm{a}$ & & $€ / a$ & $\mathrm{~m}^{3} / \mathrm{a}$ \\
\hline 2004 & 1.930 .000 & & 60.000 & 55.188 & 2.045 .188 & 122.640 & 1,00 & 2.045 .188 & 122.640 \\
\hline 2005 & 509.000 & & 120.000 & 110.376 & 739.376 & 122.640 & 1,05 & 704.168 & 116.800 \\
\hline 2006 & & & 120.000 & 110.376 & 230.376 & 122.640 & 1,10 & 208.958 & 111.238 \\
\hline 2007 & & & 120.000 & 110.376 & 230.376 & 122.640 & 1,16 & 199.007 & 105.941 \\
\hline 2008 & & & 120.000 & 110.376 & 230.376 & 122.640 & 1,22 & 189.531 & 100.896 \\
\hline 2009 & & 643.000 & 120.000 & 110.376 & 873.376 & 122.640 & 1,28 & 684.313 & 96.092 \\
\hline 2010 & & 643.000 & 120.000 & 110.376 & 873.376 & 122.640 & 1,34 & 651.727 & 91.516 \\
\hline 2011 & & 643.000 & 120.000 & 110.376 & 873.376 & 122.640 & 1,41 & 620.692 & 87.158 \\
\hline 2012 & & 643.000 & 120.000 & 110.376 & 873.376 & 122.640 & 1,48 & 591.135 & 83.008 \\
\hline 2013 & & 643.000 & 120.000 & 110.376 & 873.376 & 122.640 & 1,55 & 562.986 & 79.055 \\
\hline 2014 & & 643.000 & 120.000 & 110.376 & 873.376 & 122.640 & 1,63 & 536.177 & 75.290 \\
\hline 2015 & & 643.000 & 120.000 & 110.376 & 873.376 & 122.640 & 1,71 & 510.645 & 71.705 \\
\hline 2016 & & & 120.000 & 110.376 & 230.376 & 122.640 & 1,80 & 128.282 & 68.291 \\
\hline 2017 & & & 120.000 & 110.376 & 230.376 & 122.640 & 1,89 & 122.173 & 65.039 \\
\hline 2018 & & & 120.000 & 110.376 & 230.376 & 122.640 & 1,98 & 116.356 & 61.942 \\
\hline 2019 & & & 120.000 & 110.376 & 230.376 & 122.640 & 2,08 & 110.815 & 58.992 \\
\hline 2020 & & & 120.000 & 110.376 & 230.376 & 122.640 & 2,18 & 105.538 & 56.183 \\
\hline 2021 & & & 120.000 & 110.376 & 230.376 & 122.640 & 2,29 & 100.512 & 53.507 \\
\hline 2022 & & & 120.000 & 110.376 & 230.376 & 122.640 & 2,41 & 95.726 & 50.959 \\
\hline 2023 & & & 120.000 & 110.376 & 230.376 & 122.640 & 2,53 & 91.168 & 48.533 \\
\hline 2024 & & & 120.000 & 110.376 & 230.376 & 122.640 & 2,65 & 86.826 & 46.222 \\
\hline 2025 & & & 120.000 & 110.376 & 230.376 & 122.640 & 2,79 & 82.692 & 44.021 \\
\hline 2026 & & & 120.000 & 110.376 & 230.376 & 122.640 & 2,93 & 78.754 & 41.924 \\
\hline 2027 & & & 120.000 & 110.376 & 230.376 & 122.640 & 3,07 & 75.004 & 39.928 \\
\hline 2028 & & & 120.000 & 110.376 & 230.376 & 122.640 & 3,23 & 71.432 & 38.027 \\
\hline 2029 & & & 120.000 & 110.376 & 230.376 & 122.640 & 3,39 & 68.031 & 36.216 \\
\hline 2030 & & & 120.000 & 110.376 & 230.376 & 122.640 & 3,56 & 64.791 & 34.491 \\
\hline 2031 & & & 120.000 & 110.376 & 230.376 & 122.640 & 3,73 & 61.706 & 32.849 \\
\hline 2032 & & & 120.000 & 110.376 & 230.376 & 122.640 & 3,92 & 58.767 & 31.285 \\
\hline 2033 & & & 120.000 & 110.376 & 230.376 & 122.640 & 4,12 & 55.969 & 29.795 \\
\hline 2034 & -985.000 & -4.500 .000 & 0 & 0 & -5.485 .000 & 0 & 4,32 & -1.269 .105 & 0 \\
\hline
\end{tabular}

\begin{tabular}{|l|c|r|r|}
\hline Net Present Values of the Costs & $€$ & 7.809 .963 & \multirow{2}{*}{1.979 .541} \\
Net Present Values of the Groundwater Amounts & $\mathrm{m}^{3}$ & & \\
Dynamic Prime Cost including the additional Investment & $€ / \mathrm{m}^{3}$ & 3,95 & \\
Dynamic Prime Cost excluding the additional Investment & $€ / \mathrm{m}^{3}$ & 2,93 & \\
Dynamic Prime Cost excluding the Investment & $€ / \mathrm{m}^{3}$ & 1,82 & \\
\hline
\end{tabular}


Because the dynamic prime costs are so sensitive to the investment costs, it might have been possible to implement these additional investments over a longer time scale. We can therefore say that, depending on the implementation strategy, the dynamic prime costs of the aquifer remediation measures are in the range of $3.5 € / \mathrm{m}^{3} \pm 0.5 € / \mathrm{m}^{3}$. In comparison, the water tariff at the site is $1.2 € / \mathrm{m}^{3}$. From this perspective, the remediation action appears to be very expensive and not sustainable from the economical point of view.

\section{Other Technical/Biological Remediation Options}

In addition to the detailed investigations of the aquifer characteristics required to define the design criteria for the different water collection, treatment and injection facilities, the large-scale research project METLEN was initiated to explore the natural and enhanced natural attenuation potential of MTBE within the aquifer [1]. The project included the development of a pilot-scale on-site treatment facility for MTBE. To construct and operate this pilot plant for biological groundwater treatment was an experimental challenge. But the plant worked satisfactorily for a water flow of $2 \mathrm{~m}^{3} / \mathrm{h}$ and remediated the contaminated groundwater from an average of $10-50 \mathrm{mg} / \mathrm{L} \mathrm{MTBE}$ and $15-20 \mathrm{mg} / \mathrm{L}$ BTEX down to about $1 \mathrm{mg} / \mathrm{L}$ MTBE and less than $10 \mu \mathrm{g} / \mathrm{L}$ BTEX (at MTBE loadings up to $1 \mathrm{~g} / \mathrm{m}^{2} \cdot \mathrm{d}$ ). Therefore, an extension to full scale was considered. Thus, this type of technology combined with e.g., activated charcoal adsorption might be an alternative or at least supplementary technology for solving the MTBE contamination problem in Leuna or similar contamination problems at other sites in the future.

Although the new technology was calculated to be far less expensive than the later used conventional treatment technologies, it was not put forward due to concerns of the LAF that it is not state-of-the-art. However, with more extensive testing and proofing the technology at other sites, it might become a valuable technically and economically sustainable solution.

\section{Conclusions}

Although dynamic prime costs have the characteristics of shadow or political prices, the calculation of the dynamic prime costs confirms that eliminating the groundwater contamination that was caused in the past is quite expensive, when comparing the dynamic prime costs with the actual water tariff of $1.2 € / \mathrm{m}^{3}$ charged by the downstream water works. It would not be correct, however, to argue that the water production is unduly subsidized by public investment for protecting the Leuna aquifer because this serious environmental problem was created by past activities. This is a public investment, which balances the faults of the past with future interests of the society.

For site remediation, a conventional water treatment technology has been chosen. We calculated that, depending on the implementation strategy, the dynamic prime costs of the aquifer remediation measures are in the range of $3.5 € / \mathrm{m}^{3} \pm 0.5 € / \mathrm{m}^{3}$. In light of the existing water pricing, the remediation action appears to be very expensive. But the current water prices can only be used as a certain orientation of the magnitude of the social costs for groundwater. The sustainability of the technology solution found is reflected by the social costs for balancing the damages of past activities with the interest of future generations in a clean aquifer. 
The insight gained from a small-scale pilot remediation plant demonstrated that biological water treatment might be an alternative MTBE remediation technology in the future. In terms of sustainability, the biological approach would be as environmentally sustainable as the conventional technology at this site. However, it would very likely reduce the costs considerably.

Finally, the application of natural attenuation as remediation strategy at the Leuna site would also have been possible. This would have implied monitoring with no additional technical intervention, resulting in large cost savings. The drawback is, however, the very large aquifer volume that would be required. In addition, it is expected that this natural attenuation process would need a very long time of decades or even centuries to be completed. Therefore, in our opinion, this solution would be sustainable only if the aquifer as a local public good is not needed for other purposes.

\section{Acknowledgements}

We are grateful to B. Harpke from the "Landesanstalt für Altlastenfreistellung des Landes Sachsen-Anhalt" (LAF) (State Agency for Redemption of Liability Saxony-Anhalt) for supporting us with information about the investment and operation costs for the rehabilitation of the Leuna aquifer and comments on the MTBE case study. We also would like to thank our colleagues from the UFZ and especially Marion Martienssen (now Brandenburg University of Technology Cottbus), as well as John Molson (Laval University, Quebec, Canada) for many helpful discussions.

\section{References}

1. Martienssen, M.; Fabritis, H.; Kukla, S.; Balcke, G.U.; Hasselwander, E.; Schirmer, M. Determination of Naturally Occuring MTBE Biogradation by Analysing Metabolites and Biogradation By-Products. J. Contam. Hydrol. 2006, 87, 37-35.

2. Samuelson, P.A. The Theory of Public Expenditures. Rev. Econ. Stat. 2007, 36, 387-389.

3. Musgrave, R.A. The Theory of Public Finance; Mc Graw-Hill: New York, NY, USA, 1956.

4. Tiebout, C. A Pure Theory of Local Expenditure. JPE 1956, 5, 416-424.

5. Schirmer, M.; Martienssen, M. Enhanced Natural Attenuation of MTBE. In The Handbook of Environmental Chemistry; Barcelo, D., Ed.; Springer: Berlin/Heidelberg, Germay, 2007; Volume 5, pp. 136-158.

6. Schirmer, M. Das Verhalten des Benzininhaltstoffes Methylteriärbutylether (MTBE) in Grundwasser. Grundwasser 1999, 4, 95-102.

7. Javanmardian, M.; Glasser, H.A. In situ Bio Degradation of MTBE Using Bio Sparging. In Preprints of Papers-Proceedings of the 213th ACS National Meeting, San Francisco, CA, USA, 13-17 April 1997; Volume 37, No. 1, p. 424.

8. Leeson, A.; Johnson, P.C.; Johnson, R.L.; Vogel, C.M.; Hinchee, R.E.; McWorther, D.B. Air Sparging Design Paradigm; Batelle: Columbus, OH, USA, 2002.

9. Salanitro, J.P.; Johnson, P.C.; Spinnler, G.E.; Maner, P.M.; Wisniewski, H.L.; Bruce, C. Field Scale Demonstration of Enhanced MTBE Bio Remediation through Aquifer Bio Augmentation and Oxygation. Int. Environ. Sci. Technol. 2000, 34, 152-162.

10. Wilson, J.P.; Mackay, D.M.; Scow, K.M. In Situ MTBE Bio Degradation Supported by Diffusive Oxygen Release. Int. Environ. Sci. Technol. 2002, 36, 90-199. 
11. Smith, A.E.; Hristova, K.; Wood, I.; Mackay, D.M.; Lory, E.; Lorenzana, D.; Scow, K.M. Comparison of Bio Stimulation Versus Bio Augmentation with Bacterial Strain PM1 for Treatment of Groundwater Contaminated with Methyl Tertiary Butyl Ether (MTBE). Environ. Health Perspect. 2005, 113, 317-322.

12. Balcke, G.U.; Paschke, H.; Vogt, C.; Schirmer, M. Pulsed gas injection: A minimum effort approach for enhanced natural attenuation of contaminated aquifers. Environ. Pollut. 2009, 157, 2011-2018.

13. Geistlinger, H.; Eisermann, D.; Beckmann, A.M.; Schirmer, M. Mass Transfer Models: From Bench Scale to Field Scale. In Proceedings of the Model Care Conference, Den Haag, The Netherlands, 6-9 June 2005.

14. Harpke, B.; Müller, H.; Endrisczewitz, M.; Hasselwander, E. MTBE-Sanierung am Standort Leuna. Sicherung und Sanierung des Grundwasserabstroms der alten Raffinerie mit Dichtwand und Reinigungsanlage. Terra. Tech. 2006, 5, 13-16.

15. Niemes, H.; Schirmer, M. Entropy, Water and Resources. An Essay in Natural Sciences-Consistent Economics; Springer Physica: Heidelberg, Germay, 2010.

(C) 2010 by the authors; licensee MDPI, Basel, Switzerland. This article is an Open Access article distributed under the terms and conditions of the Creative Commons Attribution license (http://creativecommons.org/Licenses/by/3.0/). 